\title{
Difference in Biomarkers Between COVID-19 Patients and Other Pulmonary Infection Patients
}

This article was published in the following Dove Press journal:

Infection and Drug Resistance

\author{
Jingyi Dai ${ }^{1, *}$ \\ Yingrong Du $\mathbb{D}^{1, *}$ \\ Jianpeng Gao I,* \\ Jun Zhao $\mathbb{1 D}^{2}$ \\ Lin Wang ${ }^{3}$ \\ Ying Huang' \\ Jiawei $\mathrm{Xia}^{4}$ \\ Yu Luo' \\ Shenghao $\mathrm{Li}^{4}$ \\ Edward B McNeil $\mathbb{D}^{5}$ \\ 'Department of Infectious Diseases, \\ Kunming Third People's Hospital, \\ Kunming, Yunnan, People's Republic of \\ China; ${ }^{2}$ School of Public Health and \\ Management, Hubei University of \\ Medicine, Shiyan, Hubei, People's \\ Republic of China; ${ }^{3}$ Department of \\ Clinical Laboratory, Kunming Third \\ People's Hospital, Kunming, Yunnan, \\ People's Republic of China; ${ }^{4}$ Department \\ of Critical Care Medicine, Kunming Third \\ People's Hospital, Kunming, Yunnan, \\ People's Republic of China; \\ ${ }^{5}$ Epidemiology Unit, Faculty of Medicine, \\ Prince of Songkla University, Hat Yai, \\ Songkhla, Thailand \\ *These authors contributed equally to \\ this work
}

Correspondence: Jun Zhao

School of Public Health and Management,

Hubei University of Medicine, 30 South

Renmin Road, Shiyan, Hubei 442000,

People's Republic of China

Tel +86-7| $9-8891135$

Fax +86-719-8875336

Email stzhao@।63.com
Background: The pandemic due to the novel coronavirus disease 2019 (COVID-19) has resulted in an increasing number of patients need to be tested. We aimed to determine if the use of integrated laboratory data can discriminate COVID-19 patients from other pulmonary infection patients.

Methods: This retrospective cohort study was conducted at Kunming Third People's Hospital in China from January 20 to February 28, 2020. Medical records and laboratory data were extracted and combined for COVID-19 and other pulmonary infection patients on admission. A partial least square discriminant analysis (PLS-DA) model was constructed and calibrated to discriminate COVID-19 from other pulmonary infection patients.

Results: COVID-19 patients diagnosed and treated in Kunming were balanced in terms of sex and covered all age groups. Most of them were mild cases; only five were severe cases. The first two dimensions of the PLS-DA model could classify COVID-19 and other pulmonary infection patients with an accuracy of $96.6 \%(95.1 \%$ in the cross-validation model). Basophil count, the proportion of basophils, prothrombin time, prothrombin time activity, and international normalized ratio were the five most discriminant biomarkers.

Conclusion: Integration of biomarkers can discriminate COVID-19 patients from other pulmonary infections on admission to hospital and thus may be a supplement to nucleic acid tests.

Keywords: COVID-19, biomarker, pneumonia, partial least square discriminant analysis

\section{Introduction}

On December 31, 2019, Wuhan municipal health commission of Hubei province, China, first announced a cluster of unexplained cases of pneumonia. The outbreak of pneumonia was subsequently identified to be caused by the 2019 Novel Coronavirus (2019-nCoV). ${ }^{1}$ On February 11, 2020, the disease was christened Corona Virus Disease (COVID-19) by the World Health Organization (WHO). As of February 29, 2020, a total of 79,394 and 6264 patients were reported to have been infected in China and in other countries, respectively.

In China, the COVID-19 cases were confirmed by using real-time fluorescent reverse transcriptase polymerase chain reaction (RT-PCR) nucleic acid test, or the virus gene sequencing. ${ }^{2}$ Before January 23, 2020, only the Centers for Disease Control and Prevention was qualified to use these tests to confirm COVID-19 infection. Doctors in local areas diagnosed suspected cases based on patients' epidemiological history of the surrounding sojourn in Wuhan area, clinical manifestations, blood cell assay, and computed tomography (CT) scan. Importantly, some individuals who tested positive for the virus were asymptomatic ${ }^{3}$ and some 
COVID-19 patients did not have abnormal radiologic findings on CT scan. ${ }^{4}$ Control and prevention of the disease is especially difficult in China and elsewhere if there were infected individuals with no clinical symptoms or signs. Thus, identifying the integrated effects on detectable biomarkers in the blood resulting from immune damage to COVID-19 is necessary. Herein, we documented the clinical features and laboratory findings of patients in Yunnan province infected with SARS-Cov-2 and other pulmonary infections. Our aim was to find differences in biomarkers between COVID-19 patients and other pulmonary infection patients. Our hypothesis is that integrated laboratory data can discriminate individuals with COVID-19 and other pulmonary infections.

\section{Patients and Methods}

\section{Patients}

This retrospective cohort study was conducted at Kunming Third People's Hospital in China. This hospital is the designated hospital for the treatment of patients with COVID-19 in Kunming city. During the outbreak, 39 COVID-19 patients were admitted, of which three were asymptomatic, five were severe, and 31 were mild. We extracted electronic medical records of hospitalized COVID-19 patients admitted from January 20 to February 28, 2020. COVID-19 was diagnosed on the basis of the WHO interim guidance. ${ }^{5}$ A team of two experienced specialists in COVID-19 diagnosis and treatment identified COVID-19 and other pulmonary infection patients in the corresponding period after a review of each patient's chart.

The National Medical Products Administration started the emergency approval procedure for the COVID-19 nucleic acid detection kit during the public health emergency. The real-time RT-PCR tests for COVID-19 nucleic acid were performed using nasopharyngeal swabs (Novel Coronavirus PCR Fluorescence Diagnostic Kit, Shanghai bio-germ Medical Technology Co Ltd). A confirmed COVID-19 case was defined as a positive result of real-time RT-PCR nucleic acid. The real-time RT-PCR assay was performed using a COVID-19 nucleic acid detection kit according to the manufacturer's protocol. Patients were excluded if they had HIV infection.

A batch of biomarkers was assayed in blood samples of pulmonary infection patients and COVID-19 cases within 24 hours of admission prior to medication. All laboratory examinations were performed according to the clinical needs of the patient. We collected routine laboratory examinations including complete blood count, infection markers, coagulation function, and serum biochemical tests (liver function, renal function, myocardial enzyme, and electrolytes) that had been performed on admission. A total of 34 biomarkers were included in the analysis. They were: white blood cell count (WBC), neutrophil count (NEUT), proportion of neutrophils (NEUT\%), eosinophils count (EOS), proportion of eosinophils (EOSP), basophils count (BAS), proportion of basophils (BASP\%), lymphocyte count (LYM), proportion of lymphocytes (LYMP), monocytes count (MONO), proportion of monocytes (MONOP), red blood cell count (RBC), haemoglobin (HGB), platelet count (PLT), prothrombin time (PT), prothrombin time activity (PTA), international normalized ratio (INR), fibrinogen (FIB), total bilirubin (TB), direct bilirubin (DB), indirect bilirubin (IB), aspartate aminotransferase (AST), alanine aminotransferase (ALT), albumin (ALB), globin (GLB), total protein (TP), urea (UREA), creatinine (CRE), uric acid (UA), creatine kinase (CK), lactic dehydrogenase (LDH), myoglobin (MYO), procalcitonin (PCT), and C-reactive protein (CRP). We combined the medical records and laboratory data using each patient's hospital identification number.

\section{Ethics Statement}

This study was approved by the Ethics Committee of Kunming Third People's Hospital. Patient consent to review their medical records was not required by the ethics committees. The names and identification numbers of all patients were encrypted before use to ensure confidentiality. Approval to conduct the study was done in compliance with the Declaration of Helsinki.

\section{Statistical Analysis}

We summarized patients' characteristics and clinical features as frequency counts and percentages. Chi-square tests were used to examine univariate associations between COVID-19 patients and other pulmonary infection patients. We used either means and standard deviations or medians with interquartile ranges to describe the biomarker variables depending on their distribution. Differences in biomarkers between COVID-19 patients and other pulmonary infection patients were assessed via Student's $t$-tests or Wilcoxon rank-sum tests. Two-tailed $P$ values were reported with values less than 0.05 considered as significant. 
Since the number of biomarkers is large, and many of them have a strong correlation with each other, the relationship between type of infection and biomarkers was explored by constructing and validating a partial least square discriminant analysis (PLS-DA) model. ${ }^{6}$ This type of model can handle highly correlated predictors. Prior to PLS-DA modelling, non-normally distributed biomarker variables were transformed using their natural logarithm. All biomarker variables were also centered and scaled. Five-fold crossvalidation repeated 100 times was performed to calibrate the model. The PLS-DA method is implemented via the mixOmics ${ }^{7}$ package in $\mathrm{R}$ version 3.6.1, which was used to perform all analyses and visualizations. ${ }^{8}$

\section{Results}

\section{Patients' Demographic and Clinical Characteristics}

A total of 88 pulmonary infection patients were included in the study, of which 39 were due to COVID-19 and 49 were due to other infections. A comparison of demographic and clinical characteristics of the two groups of patients is shown in Table 1. The mean age of all patients was 39.1 years ( $\pm 18.4 \mathrm{SD})$, and $45.5 \%$ were females. No significant differences among groups were observed with regard to age, sex, and symptoms on hospital admission. The comorbidities of the patients included hypertension (17), diabetes (9), chronic liver disease (5), and chronic kidney disease (2). The distribution of underlying diseases in the two groups was not statistically different. The mean duration from symptoms onset to hospitalization for the 39 COVID19 patients was 5.2 ( $\pm 4.7 \mathrm{SD})$ days and was not significantly different from that of the 49 patients with other infections (mean $=7.1, \mathrm{SD}=3.6$ days).

Among the 39 COVID-19 patients, 10 (25.6\%) were aged 18-39 years, $15(38.5 \%)$ were aged $40-59$ years, $6(15.4 \%)$ were aged less than 18 years, and $8(20.5 \%)$ were aged 60 years or more. The mean age was 41.9 years ( $\pm 19.6 \mathrm{SD})$. The most common symptoms at illness onset were cough $(21,53.8 \%)$, fever $(13,33.3 \%)$, muscle soreness $(11,28.2 \%)$, chills $(10,25.6 \%)$, fatigue $(9,23.1 \%)$, diarrhea $(6,15.4 \%)$ and chest congestion $(4,10.3 \%)$. Of the 39 COVID-19 patients, three were asymptomatic cases, while five were severe cases and were transferred to an intensive care unit for treatment. Of the 49 other pulmonary infections, two were severe cases.

The biomarkers taken on admission from the two groups of patients are shown in Table 2. Univariate analysis showed that there were significant differences in some of the biomarkers between the two groups of patients. The biomarkers from blood cell analysis including WBC, BAS, BASP, and LYM, liver and renal metabolism function including AST, TP, UA, MYO, and CK coagulation regulation including PT, INR, and PTA, were significantly different from patients with other pulmonary infections. Lymphocytopenia was common for both groups while BASP, LYM and WBC for patients with COVID-19 were lower than that for patients with other pulmonary infections.

\section{Patients' Classification According to PLS-DA}

In order to verify the specific patterns of biomarkers in different types of infections, a PLS-DA model using all the 34 biomarkers was constructed and validated. Figure 1 shows a cluster map of the samples based on the first two dimensions of the PLS-DA model. The discriminant ability of the model is evident; a clear separation between samples assigned to the two types of infections can be observed. There is no overlap between the $95 \%$ confidence ellipses which indicates that the model has a high discriminant ability. Only three patients (Nos. 17, 36, and 84) were misclassified. No. 17 and No. 36 belonged to a four-yearold boy and a three-year-old girl, respectively. They were the youngest two COVID-19 patients. No. 84 belonged to a 46-year-old female with other pulmonary infections. The percentage of correct classification using the first two dimensions was $96.6 \%$ in the PLS-DA model $(95.1 \%$ in the five-fold cross-validation model).

To identify the most discriminant subset of biomarkers, we examined the relationship between each biomarker and the two dimensions. Figure 2 shows a correlation circle plot of the correlation coefficients. The biomarkers PT, PTA, INR, BAS, and BAS\% had a very strong correlation with the first dimension, but little correlation with the second. Of these five biomarkers, PTA was negatively correlated with the first dimension, while the other four were positively correlated. The biomarkers NEUT, NEUT $\%, \mathrm{WBC}, \mathrm{LDH}, \mathrm{DB}$ and $\mathrm{LYM} \%$ had strong correlations with the second dimension, but little correlation with the first. Of these six biomarkers, LYM\% was negatively correlated with the second dimension, while the other five were positively correlated. The correlation coefficients between all other biomarkers and the two dimensions were less than 0.5 , which indicates that they contributed little to the discrimination of the two types of infections. 
Table I Demographic and Clinical Characteristics of 88 Patients with COVID-19 and Other Pulmonary Infections on Hospital Admission in Kunming, Yunnan Province, China

\begin{tabular}{|c|c|c|c|c|}
\hline & \multirow{2}{*}{$\begin{array}{l}\text { All } \\
\text { Patients } \\
(n=88)\end{array}$} & \multicolumn{2}{|c|}{$\begin{array}{l}\text { Type of Pulmonary } \\
\text { Infection }\end{array}$} & \multirow[t]{2}{*}{$P$ value } \\
\hline & & $\begin{array}{l}\text { COVID-19 } \\
(n=39)\end{array}$ & $\begin{array}{l}\text { Others } \\
(n=49)\end{array}$ & \\
\hline Age group (years) & & & & 0.256 \\
\hline$<18$ & $12(13.6)$ & $6(15.4)$ & $6(12.2)$ & \\
\hline $18-39$ & $30(34.1)$ & $10(25.6)$ & $20(40.8)$ & \\
\hline $40-59$ & $33(37.5)$ & $15(38.5)$ & $18(36.7)$ & \\
\hline$\geq 60$ & $13(14.8)$ & $8(20.5)$ & $5(10.2)$ & \\
\hline Sex & & & & 0.232 \\
\hline Female & $40(45.5)$ & $21(53.8)$ & $19(38.8)$ & \\
\hline Male & $48(54.5)$ & $18(46.2)$ & $30(61.2)$ & \\
\hline $\begin{array}{l}\text { Highest } \\
\text { temperature }\left({ }^{\circ} \mathrm{C}\right)\end{array}$ & & & & 0.632 \\
\hline$<37.5$ & $54(61.4)$ & $26(66.7)$ & $28(57.1)$ & \\
\hline $37.5-38$ & $12(13.6)$ & $5(12.8)$ & $7(14.3)$ & \\
\hline$>38$ & $22(25.0)$ & $8(20.5)$ & $14(28.6)$ & \\
\hline Cough & & & & 0.203 \\
\hline No & $33(37.5)$ & $18(46.2)$ & $15(30.6)$ & \\
\hline Yes & $55(62.5)$ & $21(53.8)$ & $34(69.4)$ & \\
\hline Chills & & & & 0.104 \\
\hline No & $73(83.0)$ & $29(74.4)$ & $44(89.8)$ & \\
\hline Yes & $15(17.0)$ & $10(25.6)$ & $5(10.2)$ & \\
\hline Muscle soreness & & & & 0.058 \\
\hline No & $72(81.8)$ & $28(71.8)$ & $44(89.8)$ & \\
\hline Yes & $16(18.2)$ & II (28.2) & $5(10.2)$ & \\
\hline Fatigue & & & & 0.433 \\
\hline No & $72(81.8)$ & $30(76.9)$ & $42(85.7)$ & \\
\hline Yes & $16(18.2)$ & $9(23.1)$ & $7(14.3)$ & \\
\hline Chest congestion & & & & 0.446 \\
\hline No & $75(85.2)$ & 35 (89.7) & $40(81.6)$ & \\
\hline Yes & $13(14.8)$ & $4(10.3)$ & $9(18.4)$ & \\
\hline Diarrhea & & & & 0.289 \\
\hline No & $78(88.6)$ & $33(84.6)$ & $45(91.8)$ & \\
\hline Yes & $10(11.4)$ & $6(15.4)$ & $4(8.2)$ & \\
\hline Hypertension & & & & 0.600 \\
\hline No & 71 (80.7) & $30(76.9)$ & $4 \mathrm{l}(83.7)$ & \\
\hline Yes & $17(19.3)$ & $9(23.1)$ & $8(16.3)$ & \\
\hline Diabetes & & & & 0.999 \\
\hline No & $79(89.8)$ & $35(89.7)$ & $44(89.8)$ & \\
\hline Yes & $9(10.2)$ & $4(10.3)$ & $5(10.2)$ & \\
\hline Hepatic disease & & & & 0.377 \\
\hline No & $83(94.3)$ & $38(97.4)$ & $45(91.8)$ & \\
\hline Yes & $5(5.7)$ & I (2.6) & $4(8.2)$ & \\
\hline
\end{tabular}

(Continued)
Table I (Continued).

\begin{tabular}{|c|c|c|c|c|}
\hline & \multirow{2}{*}{$\begin{array}{l}\text { All } \\
\text { Patients } \\
(n=88)\end{array}$} & \multicolumn{2}{|c|}{$\begin{array}{l}\text { Type of Pulmonary } \\
\text { Infection }\end{array}$} & \multirow[t]{2}{*}{$P$ value } \\
\hline & & $\begin{array}{l}\text { COVID-19 } \\
(n=39)\end{array}$ & $\begin{array}{l}\text { Others } \\
(n=49)\end{array}$ & \\
\hline Renal disease & & & & 0.501 \\
\hline No & 86 (97.7) & $39(100)$ & 47 (95.9) & \\
\hline Yes & $2(2.3)$ & $0(0)$ & $2(4.1)$ & \\
\hline
\end{tabular}

\section{Discussion}

Our study demonstrated differences in biomarkers between COVID-19 patients and other pulmonary infection patients. We used a PLS-DA model analysis and identified that the most discriminating biomarkers were BAS, BASP, PTA, PT, and INR.

The COVID-19 patients in Kunming were balanced in terms of sex and covered all age groups. This finding is consistent with results reported from other areas outside Wuhan. ${ }^{9}$ Symptoms of COVID-19 patients were not significantly different from those of other pulmonary infection patients. The symptoms of SARS-Cov-2 infection are atypical, most have only low fever, and are similar to other pulmonary infections, which leads to many early-stage COVID-19 patients missed. The patients admitted to the ICU were older and had a greater number of comorbid conditions than those not admitted to the ICU. Clinical symptoms are not obviously serious among COVID-19 cases and may be explained by molecule virology: SARSCov-2 likely uses human angiotensin-converting enzyme 2 as the entry receptor, ${ }^{10-12}$ which is found primarily in the lower respiratory tract, rather than in the upper airway. ${ }^{13}$ Only $5(12.8 \%)$ of the 39 confirmed COVID-19 cases in this study were admitted to the intensive care unit, whereas in Wuhan, based on early reports, the percentage was in the range of $26-32 \% .^{2,14}$ A biological mechanism such as antibody-dependent enhancement occurring may explain the geographic discrepancy in the severity of cases. ${ }^{15}$

We compared, between the two groups of confirmed cases, several characteristics including severe, common, and asymptomatic cases, as well as pneumonia-absent cases, with other pulmonary infections. We found some clinical characteristics that differentiated COVID-19 from other pulmonary infections. Lymphocytopenia was common in both groups and was consistent with the results of 
Table 2 Biomarkers in Patients with COVID-19 and Other Pulmonary Infections on Hospital Admission in Yunnan Province, China

\begin{tabular}{|c|c|c|c|c|}
\hline \multirow[t]{2}{*}{ Biomarker } & \multirow[t]{2}{*}{ All Patients $(n=88)$} & \multicolumn{2}{|c|}{ Pulmonary Infection } & \multirow[t]{2}{*}{$P$ value } \\
\hline & & COVID-I $9(n=39)$ & Others $(n=49)$ & \\
\hline White blood cell count ( $10^{9}$ cells per $\left.\mathrm{L}\right)$ & $5.64(4.55,7.34)$ & $5.09(3.88,6.29)$ & $5.99(5.13,7.75)$ & 0.006 \\
\hline Neutrophil count $\left(10^{9}\right.$ cells per $\left.\mathrm{L}\right)$ & $3.61(2.60,4.8 I)$ & $3.47(2.56,4.38)$ & $3.95(2.62,5.08)$ & 0.220 \\
\hline Proportion of neutrophils (\%), mean (SD) & $59.1(13.8)$ & $60.8(14.6)$ & $57.8(13.1)$ & $0.306^{\dagger}$ \\
\hline Eosinophils count ( $10^{9}$ cells per $\left.\mathrm{L}\right)$ & $0.06(0.03,0.13)$ & $0.06(0.03,0.08)$ & $0.08(0.03,0.17)$ & 0.325 \\
\hline Proportion of eosinophils (\%) & $1.20(0.50,2.30)$ & $1.04(0.50,2.05)$ & $1.50(0.50,2.40)$ & 0.534 \\
\hline Basophils count ( $10^{\circ}$ cells per $\left.\mathrm{L}\right)$ & $0.02(0.01,0.04)$ & $0.01(0.00,0.01)$ & $0.03(0.02,0.05)$ & $<0.001$ \\
\hline Proportion of basophils (\%) & $0.30(0.13,0.70)$ & $0.10(0.00,0.20)$ & $0.60(0.40,0.70)$ & $<0.001$ \\
\hline Lymphocyte count ( $10^{\circ}$ cells per $\mathrm{L}$ ), mean (SD) & $1.75(0.73)$ & $1.50(0.56)$ & $1.95(0.79)$ & $0.003^{\dagger}$ \\
\hline Proportion of lymphocyte, mean (SD) & $30.1(11.3)$ & $29.1(10.9)$ & $30.9(11.6)$ & $0.469^{\dagger}$ \\
\hline Monocytes count ( $10^{\circ}$ cells per $\left.\mathrm{L}\right)$ & $0.46(0.36,0.61)$ & $0.43(0.34,0.55)$ & $0.46(0.38,0.68)$ & 0.217 \\
\hline Proportion of monocytes, mean (SD) & $8.08(2.7 \mathrm{I})$ & $7.83(2.80)$ & $8.27(2.65)$ & $0.45 \mathrm{I}^{\dagger}$ \\
\hline Red blood cell count ( $10^{\circ}$ cells per $\mathrm{L}$ ), mean (SD) & $4.69(0.62)$ & $4.67(0.61)$ & $4.70(0.63)$ & $0.809^{\dagger}$ \\
\hline Haemoglobin $(g / L)$, mean $(S D)$ & $143.1(18.63)$ & $141.15(17.6)$ & $144.6(19.5)$ & $0.399^{\dagger}$ \\
\hline Platelet count ( $10^{9}$ cells per $\left.\mathrm{L}\right)$ & $246.5(188.5,297.3)$ & $251.0(202.5,313.5)$ & $231.0(182.0,290.0)$ & 0.218 \\
\hline Prothrombin time (s) & $12.3(9.1,13.2)$ & $8.94(8.39,9.68)$ & $13.1(12.7,13.8)$ & $<0.001$ \\
\hline Prothrombin time activity (\%), mean (SD) & $93.6(23.3)$ & II $2.5(17.4)$ & $76.9(12.5)$ & $<0.00 \mathrm{I}^{\dagger}$ \\
\hline International normalized ratio & $0.97(0.77,1.07)$ & $0.77(0.72,0.82)$ & $1.07(1.01,1.13)$ & $<0.001$ \\
\hline Fibrinogen $(g / d L)$ & $3.24(2.61,4.22)$ & $3.34(2.59,4.2)$ & $3.15(2.72,4.17)$ & 0.769 \\
\hline Total bilirubin $(\mu \mathrm{mol} / \mathrm{L})$ & II.I $(8.07,15.6)$ & $10.2(7.70,14.25)$ & I2.I (8.50, I8.95) & 0.176 \\
\hline Direct bilirubin $(\mu \mathrm{mol} / \mathrm{L})$ & $3.0(2.2,4.0)$ & $3.30(2.30,4.05)$ & $2.9(2.15,3.90)$ & 0.485 \\
\hline Indirect bilirubin $(\mu \mathrm{mol} / \mathrm{L})$ & $8.90(6.25,13.80)$ & $8.10(6.20,10.85)$ & $10.0(6.50,15.2)$ & 0.127 \\
\hline Aspartate aminotransferase (U/L) & $22.0(17.5,29)$ & $20.0(15.0,25.5)$ & $24.5(19.8,34.3)$ & 0.002 \\
\hline Alanine aminotransferase (U/L) & $23.6(14.7,33.0)$ & $23.2(15.4,32.3)$ & $24.0(13.5,33.5)$ & 0.849 \\
\hline Albumin (g/L), mean (SD) & $40.0(6.17)$ & $40.4(6.56)$ & $39.7(5.87)$ & $0.628^{\dagger}$ \\
\hline Globin $(g / L)$ & $28.7(25.9,32.4)$ & $29.3(26.85,33.35)$ & $28.2(25.7,31.0)$ & 0.074 \\
\hline Total protein $(\mathrm{g} / \mathrm{L})$ & $68.7(65.6,72.8)$ & $70.3(66.9,73.35)$ & $67.9(64.3,71.3)$ & 0.034 \\
\hline Urea $(\mathrm{mmol} / \mathrm{L})$ & $3.68(2.84,4.90)$ & $3.10(2.60,4.55)$ & $3.84(3.20,4.90)$ & 0.075 \\
\hline Creatinine $(\mu \mathrm{mol} / \mathrm{L})$ & $59.8(48.3,75.0)$ & $58.0(46.2,70.2)$ & $61.5(49.0,75.0)$ & 0.209 \\
\hline Uric acid $(\mu \mathrm{mol} / \mathrm{L})$ & $296.1(243.5,366.7)$ & $281(207,362)$ & $310(265,380)$ & 0.038 \\
\hline Creatine kinase (U/L) & $77.1(57.7,106.5)$ & $63.8(51.7,90.25)$ & $87.0(71.0,126.5)$ & 0.005 \\
\hline Lactic dehydrogenase (U/L) & $186.0(156.0,234.0)$ & $175.0(147.0,215.5)$ & $198.0(163.0,238.0)$ & 0.123 \\
\hline Myoglobin $(\mu \mathrm{g} / \mathrm{L})$ & $21.0(18.2,26.2)$ & I8.02 (15.35, 23.34) & $21.0(21.0,31.3)$ & $<0.001$ \\
\hline Procalcitonin (ng/mL) & $0.05(0.04,0.05)$ & $0.05(0.05,0.05)$ & $0.04(0.02,0.1)$ & 0.425 \\
\hline C-reactive protein (mg/L) & $2.75(0.98,12.12)$ & $2.67(0.96,6.75)$ & $3.0(1.2,18.5)$ & 0.351 \\
\hline
\end{tabular}

Notes: Values are medians (interquartile ranges) unless stated otherwise; ${ }^{\dagger}$-test.

recent reports. ${ }^{2,4,16}$ Since young children normally have a higher lymphocyte count, this may explain why sample No.17, a confirmed COVID-19 case, was more similar to the other pulmonary infection patients (Figure 1).

The most discriminating biomarkers in the PLS-DA model were BAS, BASP, PTA, PT, and INR. Decreasing basophils is common in COVID-19 patients indicating that basophils are effector cells in COVID-19 infection. Basophils play an important role in the production of $\mathrm{T}$ lymphocytes which are critical for immune function. In vitro, basophils are able to alter lymphocyte responses; ${ }^{17}$ in vivo, they may drive the development of $\mathrm{T}$ helper type 2 immunity, ${ }^{18-20}$ and enhance antibody production in protective immunity ${ }^{21}$ and in autoimmunity. ${ }^{22}$ Reduction in basophilic granulocytes may mark the onset of COVID-19 disruption of adaptive immunity from infection, since basophils seem to control the adaptive immunity of infection. ${ }^{17}$ Some of the coagulation parameters were different between COVID-19 patients and other pulmonary infection patients. Relatively lower PT and INR and relatively higher PTA were found in COVID-19 patients, which indicates that they were in a state of relatively higher coagulation. The higher coagulation state may be related to absence of plasminogen and this can blunt inflammation in response to several inflammatory 


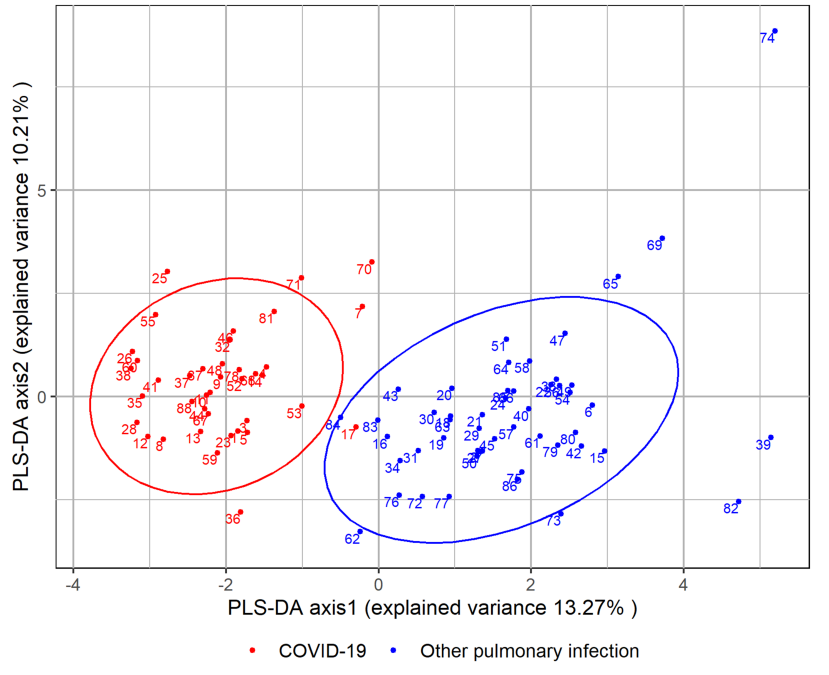

Figure I Map of the samples into the first two dimensions of the PLS-DA model. The points represent dimension scores of the projection of high-dimensional feature vectors onto the first ( $x$ axis) and second ( $y$ axis) dimensions.

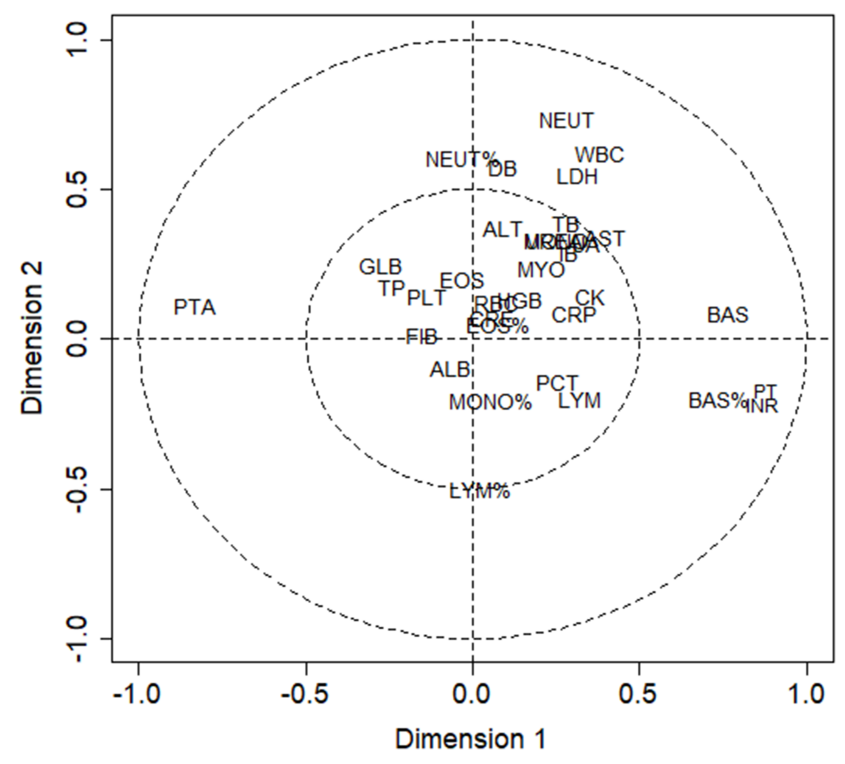

Figure 2 Correlation circle plot for the first two dimensions of the PLS-DA model.

stimuli and even suppresses the development of lesions. ${ }^{23-26}$ This could explain the extent of clinical inflammation symptoms being not obvious in COVID-19 patients. As COVID19 progresses, it is very likely that the proinflammatory properties of plasminogen will play a significant role in the pathogenesis of this infection in severe cases. A study conducted in Wuhan found that coagulation activation and secondary hyperfibrinolysis occurred in severe COVID-19 patients, and presumably, fibrinolysis may also be induced. ${ }^{27}$

Our study has several limitations. First, the medical information of some cases was documented only very briefly and laboratory testing was incomplete. There were several types of infections included in the other pulmonary group; however, most were unknown to our hospital - the infections were confirmed by the Centers for Disease Control who could only guarantee that they did not have COVID-19. Some viral infections may have been missed in this study because only a limited number of viruses were screened in the assay. Therefore, we could not include more potential confounders such as other biomarkers in our model. Second, the relatively small sample size prevents us from performing external validation of the model or subgroup analyses. Third, the generalization of our results is limited and thus needs to be verified by further studies. Although our analyses provided some differences of integrated factors from biomarkers between COVID-19 patients and other pulmonary infection patients, the integrated factors are not a sufficient condition to confirm whether the patient is infected with COVID-19. Further studies are required to understand the mechanisms of biomarkers of the immune response in COVID-19 patients.

Control and prevention of a disease is extremely difficult if infected individuals are asymptomatic. ${ }^{28}$ Identification and control of asymptomatic individuals are important measures to prevent transmission, ${ }^{29}$ especially in the later stages of prevention and control. Although RT-PCR has been widely deployed in diagnostic virology and has yielded few falsepositive outcomes, ${ }^{30}$ false-negatives can still occur. Asymptomatic COVID-19 cases have similar integrated factors of biomarkers to symptomatic cases. The integrated factors of biomarkers of COVID-19 cases are significantly different from other pulmonary infection patients. Integration of bio-markers can identify COVID-19 patients from other pulmonary infections on admission in the corresponding period. We expect that our results could be used as a supplement to nucleic acid tests and provide clues to the blood analysis of COVID-19 patients.

\section{Acknowledgments}

We thank Mr. Jinyu Duan for his help in data collection. This work was supported by "The Project of Health Science and Technology Talents Ten Hundred Thousand' in Kunming". This work was also supported by the Cultivating Project for Young Scholar at Hubei University of Medicine (Grant No. 2018QDJZR14).

\section{Disclosure}

The authors report no conflicts of interest in this work. 


\section{References}

1. Lu R, Zhao X, Li J, et al. Genomic characterisation and epidemiology of 2019 novel coronavirus: implications for virus origins and receptor binding. Lancet. 2020;395(10224):565-574. doi:10.1016/ S0140-6736(20)30251-8

2. Huang $\mathrm{C}$, Wang $\mathrm{Y}$, Li X, et al. Clinical features of patients infected with 2019 novel coronavirus in Wuhan, China. Lancet. 2020;395 (10223):497-506. doi:10.1016/S0140-6736(20)30183-5

3. Nishiura H, Kobayashi T, Yang Y, et al. The rate of underascertainment of novel coronavirus $(2019-\mathrm{nCoV})$ infection: estimation using Japanese passengers data on evacuation flights. $J$ Clin Med. 2020;9(2):419. doi:10.3390/jcm9020419

4. Guan W-J, Ni Z-Y, Hu Y, et al. Clinical characteristics of coronavirus disease 2019 in China. $N$ Engl J Med. 2020;382(18):1708-1720. doi:10.1056/NEJMoa2002032

5. Clinical management of severe acute respiratory infection when novel coronavirus $(2019-\mathrm{nCoV})$ infection is suspected: interim guidance; 2020. World Health Organization. https://www.who.int/ docs/default-source/coronaviruse/clinical-management-of-novel-cov. pdf. Accessed January 28, 2020.

6. Barker M, Rayens W. Partial least squares for discrimination. J Chemom. 2003;17(3):166-173. doi:10.1016/j.mri.2011.11.001

7. Schneidman D, Rohart F, Gautier B, Singh A, Lê Cao K-A. mixOmics: an R package for 'omics feature selection and multiple data integration. PLoS Comput Biol. 2017;13(11):e1005752. doi:10.1371/journal.pcbi.1005752

8. R Core Team (2019). R: A Language and Environment for Statistical Computing. Vienna, Austria: R Foundation for Statistical Computing. https://www.R-project.org/. Accessed July 20, 2020.

9. Xu XW, Wu XX, Jiang XG, et al. Clinical findings in a group of patients infected with the 2019 novel coronavirus (SARS-Cov-2) outside of Wuhan, China: retrospective case series. BMJ. 2020;368: m606. doi:10.1136/bmj.m606

10. Ling L, Gm J, Lipman J, Constantin J-M, Joannes-Boyau O. COVID19: a critical care perspective informed by lessons learnt from other viral epidemics. Anaesthesia Critical Care and Pain Med. 2020;39 (2):163-166. doi:10.1016/j.accpm.2020.02.002

11. Li W, Moore MJ, Vasilieva N, et al. Angiotensin-converting enzyme 2 is a functional receptor for the SARS coronavirus. Nature. 2003;426(6965):450-454. doi:10.1038/nature02145

12. Zhou P, Yang X-L, Wang X-G, et al. A pneumonia outbreak associated with a new coronavirus of probable bat origin. Nature. 2020;579(7798):270-273. doi:10.1038/s41586-020-2012-7

13. Paules CI, Marston HD, Fauci AS. Coronavirus infections-more than just the common cold. JAMA. 2020;323(8):707-708. doi:10. 1001/jama.2020.0757
14. Wang D, Hu B, Hu C, et al. Clinical characteristics of 138 hospitalized patients with 2019 novel coronavirus-infected pneumonia in Wuhan, China. JAMA. 2020;323(11):1061-1069. doi:10.1001/jama.2020.1585

15. Tetro JA. Is COVID-19 receiving ADE from other coronaviruses? Microbes Infect. 2020;22(2):72-73. doi:10.1016/j.micinf.2020.02.006

16. Chen N, Zhou M, Dong X, et al. Epidemiological and clinical characteristics of 99 cases of 2019 novel coronavirus pneumonia in Wuhan, China: a descriptive study. Lancet. 2020;395(10223):507-513. doi:10.1016/ S0140-6736(20)30211-7

17. Min B. Basophils: what they 'can do' versus what they 'actually do'. Nat Immunol. 2008;9(12):1333-1339. doi:10.1038/ni.f.217

18. Min B, Paul WE. Basophils and type 2 immunity. Curr Opin Hematol. 2008;15(1):59-63. doi:10.1097/moh.0b013e3282f13ce8

19. Galli SJ, Franco CB. Basophils are back! Immunity. 2008;28 (4):495-497. doi:10.1016/j.immuni.2008.03.010

20. Min B, Paul WE. Basophils: in the spotlight at last. Nat Immunol. 2008;9(3):223-225. doi:10.1038/ni0308-223

21. Chen $\mathrm{K}, \mathrm{Xu} \mathrm{W}$, Wilson $\mathrm{M}$, et al. Immunoglobulin $\mathrm{D}$ enhances immune surveillance by activating antimicrobial, proinflammatory and B cell-stimulating programs in basophils. Nat Immunol. 2009;10(8):889-898. doi:10.1038/ni.1748

22. Charles N, Hardwick D, Daugas E, Illei GG, Rivera J. Basophils and the $\mathrm{T}$ helper 2 environment can promote the development of lupus nephritis. Nat Med. 2010;16(6):701-707. doi:10.1038/nm.2159

23. O'Connell PA, Surette AP, Liwski RS, Svenningsson P, Waisman DM. S100A10 regulates plasminogen-dependent macrophage invasion. Blood. 2010;116(7):1136-1146. doi:10.1182/blood-2010-01-264754

24. Ploplis VA, French EL, Carmeliet P, Collen D, Plow EF. Plasminogen deficiency differentially affects recruitment of inflammatory cell populations in mice. Blood. 1998;91(6):2005-2009. doi:10.1016/ S0887-7963(98)80036-9

25. Moons L, Shi C, Ploplis V, et al. Reduced transplant arteriosclerosis in plasminogen-deficient mice. J Clin Invest. 1998;102(10):1788-1797. doi:10.1172/JCI3316

26. Berri F, Rimmelzwaan GF, Hanss M, et al. Plasminogen controls inflammation and pathogenesis of influenza virus infections via fibrinolysis. PLoS Pathog. 2013;9(3):e1003229. doi:10.1371/journal. ppat.1003229

27. Tang N, Li D, Wang X, Sun Z. Abnormal coagulation parameters are associated with poor prognosis in patients with novel coronavirus pneumonia. J Thromb Haemost. 2020;00:1-4. doi:10.1111/jth.14768

28. The novel coronavirus outbreak: what we know and what we don't. Cell. 2020;180(6):1034-1036. doi:10.1016/j.cell.2020.02.027

29. Tian S, Hu N, Lou J, et al. Characteristics of COVID-19 infection in Beijing. J Infect. 2020;80(4):401-406. doi:10.1016/j.jinf.2020.02.018

30. Corman VM, Landt O, Kaiser M, et al. Detection of 2019 novel coronavirus (2019-nCoV) by real-time RT-PCR. Euro Surveill. 2020;25(3):3. doi:10.2807/1560-7917.ES.2020.25.3.2000045
Infection and Drug Resistance

\section{Publish your work in this journal}

Infection and Drug Resistance is an international, peer-reviewed openaccess journal that focuses on the optimal treatment of infection (bacterial, fungal and viral) and the development and institution of preventive strategies to minimize the development and spread of resistance. The journal is specifically concerned with the epidemiology of antibiotic resistance and the mechanisms of resistance development and diffusion in both hospitals and the community. The manuscript management system is completely online and includes a very quick and fair peerreview system, which is all easy to use. Visit http://www.dovepress.com/ testimonials.php to read real quotes from published authors. 